\title{
Can Consequences Be Right-Makers?
}

\author{
Forthcoming in Philosophia
}

\begin{abstract}
This paper sets out a novel challenge to consequentialism as a theory in normative ethics. The challenge is rooted in the ontological claim that consequences of actions do not exist at the time required to be that in virtue of which actions are right or wrong, and so consequences cannot play the role attributed to them by consequentialists. The challenge takes the form of a dilemma. The consequentialist is confronted with a set of propositions she will find individually plausible but incompossible if taken in conjunction with consequentialism. The task is to restore consistency. There are ways of maintaining the view that consequences are right-makers, but they come at the cost of endorsing highly implausible and unattractive theses. Versions of what might be called quasi-consequentialism can be rendered metaphysically coherent, but these are consequentialisms in name only, and they are best seen as components of an account of practical rationality that has strong echoes of traditional natural law theory. Since this is unlikely to appeal to contemporary consequentialists, their best bet is to reject consequentialism altogether.
\end{abstract}

Key words: consequentialism; quasi-consequentialism; right-makers; natural law theory; possible worlds; practical rationality; presentism; relations

\section{Introduction}

Consequentialism begins with a claim that many find irresistible, viz., that the consequences of actions are morally significant. What can be more sensible than to insist that one take the results of actions and policies into account when evaluating them? And yet for all its initial plausibility, consequentialism has many detractors wielding many different sticks. Perhaps the fundamental complaint is that it simply delivers the wrong answers to moral questions, or delivers the right answers only after much ad hoc manoeuvring. Some emphasise the epistemological difficulties involved in knowing just 
what the consequences of any given action will be, suggesting that no form of consequentialism will prove a practical guide to action. Others stress the incommensurability of goods to be pursued. Still others insist that consequentialism ignores the most important aspects of moral situations, the nature of the intention behind the action, say, or the kind of action performed, or the general character of the agent performing the action.

These and related difficulties have received considerable attention in the literature, and together they pose a serious threat to consequentialism. But what these challenges have in common with consequentialism is the unexpressed assumption that consequences could be right-makers at least in principle. This means that ethicists consider consequentialism to be at least a coherent theoretical possibility which may or may not turn out to be mistaken or unworkable for one reason or another. The thesis of this paper, however, is that this unexpressed assumption is unwarranted. Consequentialism has yet to receive so much as a coherent formulation when considered from a metaphysical point of view. ${ }^{1}$

The challenge to the metaphysical coherence of consequentialism is rooted in the seemingly uncontroversial claim that actions and their consequences do not exist at the appropriate times for consequences to be that in virtue of which actions are right or wrong. And this simple fact makes all the difference in the world with respect to the moral implications of consequences - for consequences simply cannot play the normative role attributed to them by consequentialists. Denying this banal existence claim proves to be very difficult indeed without the adoption of implausible or otherwise unattractive metaphysical theses. ${ }^{2}$

\footnotetext{
${ }^{1}$ Of course few if any normative theorists adopt such a point of view as they go about their business. No doubt this is why the metaphysical difficulties consequentialism gives rise to have not received the attention they deserve. But if truth is one, then surely our normative theories have to cohere with our metaphysical commitments. There is also a heuristic gain to be had by bringing metaphysical reflection to bear on normative theory: Such a stance suggests new and unfamiliar lines of thought on a very old and well-aired topic indeed.

${ }^{2}$ Questions regarding the very coherence of varieties of utilitarianism have been raised before. For example, Castaneda (1968) and Bergstrom $(1973,1976)$ debated the coherence of act-utilitarianism. But no one to my knowledge, with the possible exception of Arthur Prior (see below), raises a general problem for all varieties of utilitarianism by highlighting the metaphysical problem discussed here which arises for any form of consequentialism.
} 
A word on the structure of this challenge is in order. The consequentialist is confronted with a set of propositions she will find individually plausible but incompossible if taken in conjunction with consequentialism. The challenge is to restore consistency in the face of this dilemma. The most plausible route to this end, I suggest, is to reject consequentialism. There are other ways of restoring consistency, but each comes at the cost of endorsing highly unattractive theses, or ceasing to be a distinctive approach in normative ethics.

In $\S 1$ I present the dilemma. In $\S \S 2-4$ I consider the various ways the consequentialist might respond, showing in each case how these responses fail. In §5 I gather the fruit of the previous sections. Finally I consider the altogether reasonable retort that denying the moral import of consequences is itself an unattractive and intuitively implausible thesis. I believe there is something to this, for there is no denying that in our ordinary thinking consequences do appear to matter. The challenge then is to explain why this false intuition appears plausible to serious people. I end by sketching very briefly an alternative normative theory that does as much justice as possible to the consequentialist intuition without falling into metaphysical incoherence.

The propositions of the dilemma are as follows:

We begin with two presuppositions of any normative theory.

Prop. 1. The category of entities of which moral properties can be predicated includes human actions.

This is a platitude amongst normative theorists, a presupposition of their efforts qua normative theorists. Prop. 1 captures the fact that normative theorists routinely talk of human actions being morally neutral, right, wrong, permissible, forbidden, obligatory, supererogatory, etc., and there is no suggestion amongst normative theorists that such talk is systematically confused.

Prop. 2. If an action is right/wrong, it is right/wrong in virtue of some property of the action, be it intrinsic or relational. 
Prop. 2 claims that an action "s moral status is grounded in something, the most obvious contenders being an intrinsic feature of the act (perhaps its kind) or the relation of the act to its circumstances, to its consequences, to a rule, or to its agent (or some combination of these). ${ }^{3}$ For ease of exposition, let us call whatever these grounds might be "rightmakers", using this term to refer to whatever it is that makes an action right when it is right, and wrong when it is wrong. It is part of the business of normative theorists to identify right-makers in their efforts to provide a decision procedure. Prop. 2 is neutral with respect to the nature of the right-makers. It also leaves open the possibility that there are no right-makers at all.

Prop. 3. Consequences are the only right-makers of actions.

Prop. 3 is the core intuition of consequentialism. Its distinctive claim is that the goodness or badness of consequences is not merely correlated with the rightness or wrongness of actions, so that the former are reliable indicators of the latter, but that the rightness of an action type or token is constituted by its consequences being maximally or morally adequate, and that nothing else grounds the rightness or wrongness of an action. ${ }^{4}$ Now

\footnotetext{
${ }^{3}$ Proposition 2 is consistent with both realism and anti-realism in metaethics if we characterize the antirealist as maintaining that an action"s having a moral status depends on an agent having some subjective attitude, either positive or negative, towards the action. On this account the property of rightness, say, would be a relative property of being approved of by some agent.

${ }^{4}$ Because of the centrality of this claim to the logical problem being developed here it is worth quoting some authors expressing it explicitly. Sinnott-Armstrong (2011) writes: „Consequentialism=whether an act is morally right depends only on the consequences (as opposed to circumstances, or the intrinsic nature of the act or anything that happens before the act)." (Emphasis added) Driver writes: „When a theory holds that the only thing relevant to determining whether or not an action is right are the consequences produced by that action, that account is consequentialist ${ }^{\text {ec }}(2007,40)$. Similarly Pettit writes: ,Every option ... has its value fixed by the value of its prognoses: its value is a function of the value of its different prognosese $(1997,232)$. Anthony Quinton expresses the consequentialist principle as follows: ,...that the rightness, or wrongness, of an action is determined by the goodness, or badness, of the results that flow from it..." $(1989,1)$. It is true, as we shall see below, that some consequentialists will be tempted to qualify this principle. Douglas Portmore, for example, while claiming to be a consequentialist, maintains that an act"s moral status is determined by the agent"s reasons for performing it, and that these reasons are the agent"s reasons for preferring its outcome to those of the available alternatives (Portmore, 2011). But an agent"s reasons are on the scene prior to the act itself, and by Sinnott-Armstrong"s portrayal of consequentialism, nothing that ,happens before the act" can be relevant to its rightness or wrongness. Indeed, by Portmore"s own admission, it is not obvious that this is consistent with the consequentialist principle (2011,34-38), if only because the agent's reasons, understood as mental states, are not themselves consequences of the action. Nor will it do to characterize the agent"s reasons by the content of the mental states, i.e., by the anticipated consequences of an act, for these anticipated consequences exist only in the mind"s eye or fail to exist altogether. It would seem that Portmore"s commitment to an additional principle, i.e., that morality
} 
because consequences are most naturally construed as being distinct from the actions which bring them about, consequentialism is committed to the view that the right-making features of an action are not intrinsic properties of the action itself, but are relational properties the action acquires in virtue of its relationship to its consequences, the act being morally neutral in and of itself.

Prop. 4. Real relations require the simultaneous existence of subject, term and foundations.

This proposition is expressed in the technical language of traditional metaphysics and requires some explanation. Essentially it is the claim that relations are dyadic. For purposes of illustration assume that things are so constituted that Tim is taller than Tom. The relationship in question is "... taller than ..."; the subject is Tim; the term is Tom; and the foundations of the relation are the respective heights of Tim and Tom. What makes it the case that Tim really is taller than Tom (and is not just thought to be taller than Tom, or imagined to be taller than Tom) is that subject, term and foundations exist simultaneously, and Tim ${ }^{\text {ee }}$ height is greater than Tom ${ }^{\text {ee }}$. If any of these ingredients is missing, then Tim 's being taller than Tom is not grounded in reality, and is not a real relational property of Tim.

Prop. 5. If an action is performed, it is right/wrong at the time it is performed.

I take prop. 5 to be plausible on two different sorts of grounds. First, it appears to be an assumption of most normative thinking. If one is trying to determine which of several actions to perform, and, after due deliberation, one judges one possible course of action to be the right action to take, one assumes that that action is right at the very moment one actually performs it. Similarly, one assumes that the possible actions one decides against would have been wrong at that time were they performed instead of the actually chosen action. The point of our deliberations, after all, is to identify what one ought to do now, in the circumstances one currently find oneself in. It is not part of our normal moral thinking to judge an action neutral, say, at the time of its performance while maintaining that it will have different moral properties at a later date. To be sure, very often one

cannot require us to do anything irrational, has actually led to a form of quasi-consequentialism, i.e., the abandoning of consequentialism in all but name. 
cannot be confident of the rightness or wrongness of an action at the time of its performance, and its moral status might become easier to discern as time passes; but this is an epistemological point which does not affect prop. 5.

This first line of thought is supported by a second. A widely held ontological intuition is that non-existent entities have no properties. A fortiori a non-existent entity cannot undergo change, i.e., take on new properties or lose old ones, or bring about change in other entities. This point is often expressed implicitly rather than explicitly, as when one insists that existence is not a property but a precondition of having properties (à la Hume or Kant). But Prior is admirably explicit on these points. He writes, “... the things that change are existing things, and it"s while they exist that they change, e.g., it $\mathrm{s}$ existing men, not non-existent men, that get tired and then pick up again; Julius Caesar,

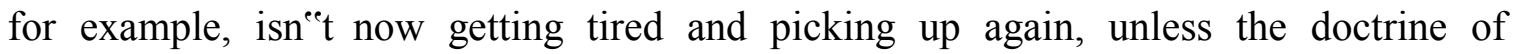
immortality is true and he exists now as much as he ever did" (1968, 3-4). ${ }^{5}$ But if an entity must exist in order to have properties, then an action, like any other actual entity, has its properties at the time it exists, that is, within the duration of the action $\mathrm{s}$ performance. A fortiori, if a performed action has the property of being right/wrong it has that property within the duration of its performance, as prop. 5 maintains. On this line of thought it is not metaphysically possible for an action to be morally neutral during its performance, say, pass out of existence, and then become either right or wrong.

Prop. 6. The consequences in virtue of which an action is right or wrong do not all exist or occur within the duration of the action"s performance.

This is a given of pre-theoretical common sense. Consequences are usually considered to be the effects or results of an action, and these can and usually do tail off into the distant future, existing long after the action has been completed. This applies even to complex actions, i.e., actions made up of basic actions, although a greater number of the set of the action $^{\text {ee }}$ s consequences do occur within the duration of the action ${ }^{e e}$ s performance. But even

\footnotetext{
${ }^{5}$ In a similar vein he writes: „Does Queen Anne"s death getting more past mean that Queen Anne has changed from having died 250 years ago to having died 251 years ago, or whatever the precise period is? that she is "getting older", though in a slightly extended sense? The trouble with this, of course, is just that Queen Anne doesn't exist now any more than her death does"e(ibid., 11).
} 
here the vast majority of the consequences will occur after the complex action has been completed.

Now while individually plausible, these propositions generate the contradiction that the consequences of an action in virtue of which it is right or wrong do and do not exist within the duration of the action es performance. For if an action is right or wrong (granted by prop. 1) at the time it is performed (prop. 5) in virtue of some simultaneously existing right-maker (props. 2 and 4), and the consequences of an action are the action ${ }^{\text {ee }}$ only right-maker (prop. 3), then those consequences must exist at the time of the action ${ }^{\text {ee }}$ s performance - a straight contradiction of prop. 6. So props. 1-6 are at least prima facie incompossible. ${ }^{6}$

How should the consequentialist respond to this dilemma? It would appear that the pressure is at least initially on prop. 3. After all, consequentialism faces serious difficulties on independent grounds, and so is plausibly regarded as the least secure of the six propositions. So the most straightforward route out of the dilemma is simply to reject consequentialism. But the consequentialist will want to explore the alternatives. These come in two general forms. Assuming that it is a dereliction of philosophical duty to ignore a contradiction ${ }^{7}$, and assuming that the consequentialist wishes to hold fast $^{8}$, she

\footnotetext{
${ }^{6}$ Something like this contradiction might just have been hinted at by Prior. In his „The Consequences of Actions ${ }^{\text {ee }}$ we read: ,...there may indeed be a number of alternative actions which we could perform on a given occasion, but none of these actions can be said to have any "total consequences", or to bring about a definite state of the world which is better than any other that might be brought about by other choices. For we may presume that other agents are free beside the one who is on the given occasion deciding what he ought to do, and the total future state of the world depends on how these others choose as well as on how the given person chooses; ... And while I speak here of one"s calculations being spoilt, the trouble of course goes deeper than that-it"s not merely that one cannot calculate the totality of what will happen if one decides in a certain way; the point is rather that there $i s$ no such totality ${ }^{\circ}(1968,51-2)$. Given his defence of presentism it is just possible that Prior was insisting here on the ontological point that forms the crux of the problem as I am developing it in this paper, not merely the epistemological challenge of ascertaining just what the "total" consequences of a given action might be.

${ }^{7}$ Of course a consequentialist might bite the bullet and accept that contradictory propositions can be true simultaneously. But this approach should be resisted because it entails that reality is ultimately unintelligible. This is simply too high a cost to incur on behalf of propositions 1-6. But a consequentialist might refuse to reject any of the propositions in the hope that the dilemma will be solved eventually as new information comes to light. This line is open to the consequentialist; but it comes at the cost of conceding that, as things stand, consequentialism fails to cohere with other apparently unproblematic beliefs.
} 
must either insist that the contradiction arising out of props. 1-6 is merely prima facie, or reject one or more of propositions $1,2,4,5$ and 6 . My intention now is simply to show that none of the various options open to the consequentialist can be made to work without substantial and unpalatable revisions to background commitments within which our normative theories are embedded. In short, the cost of saving consequentialism is simply too high.

The first way out of the dilemma is to assert that the tensions between props. 1-6 are merely prima facie, and that all six can be maintained without contradiction when properly understood. There are various ways this position might be defended, but none is particularly plausible. For instance one might suggest that there is some equivocation involved with the key terms used in props. 1-6. But the terms "action", "consequence", "exist", "duration" and "performance" appear to be used univocally throughout. Of course it is impossible to prove a negative, but the burden of proof here lies with the consequentialist, and it does not look on the face of it to be a promising line of defence. ${ }^{9}$

Changing tack, the consequentialist might grant props. 1-6 but suggest that the consequences that matter from an ethical point of view is that minuscule sub-set that does exist simultaneously with the action, so that it is true but beside the point that the vast majority of an action "s consequences fail to exist along side the action itself. But no consequentialist would be happy to so drastically curtail the consequences available to normative thinking. Indeed it would force consequentialists to institutionalise a morally absurd short-sightedness no one could seriously countenance.

\footnotetext{
${ }^{8}$ Another way out of the aporia is to reject all of props. 1-6. One might suggest that the problem has arisen because our cognitive powers or ordinary language have been applied in domains beyond their competence, and so the solution is to desist from entertaining these propositions. But this approach will not appeal to the consequentialist since it involves the rejection of consequentialism.

${ }^{9}$ A possible quibble. Some might insist, plausibly, that "exists" cannot be used in exactly the same sense of entities in different ontological categories. Thus there is an equivocation here on "exists" because actions and consequences are entities in distinct ontological categories. But this Aristotelian line of thought is really highlighting differences in the mode of existence of entities in the different categories, rather than asserting that "exists" has fundamentally unrelated senses when applied to entities in distinct categories. But more important for present purposes is the fact that consequentialists are not going to deny that either actions or consequences exist in some sense that can be applied to both.
} 
The consequentialist will naturally suggest that it is not the set of actual consequences that serve as right-makers, but only the set of expected, envisaged or intended consequences, or those that figure in the practical reasoning of the agent. That is, the consequentialist might consider retreating from what might be called objective consequentialism and regrouping around a form of subjective consequentialism. But this will not help either. These expected consequences do not exist any more than the set of actual consequences, as the subjectivist will no doubt grant. But one cannot say that the anticipatory mental state of the envisaging or intending agent serves as right-maker without giving up on consequentialism entirely - for these mental states are not the consequences of the relevant actions, and they occur before the acts happen. Similar remarks apply to those who would say that it is not the mental states themselves that count, but rather their contents, since these contents are about consequences. But the contents of thoughts about consequences are not consequences either, in the same way that the contents of thoughts about giraffes are not themselves giraffes. ${ }^{10}$ This attempt to escape the dilemma leads at best to a form of quasi-consequentialism where one continues to talk as though consequences are right-makers when in fact they are not. ${ }^{11}$ Ultimately, however, this form of quasi-consequentialism will be difficult to distinguish from other normative theories, usually thought to be competitors, which maintain that the agent $^{\text {ee }}$ s intentions and motivations are (among the) right-makers of actions.

Another obvious suggestion is that the rightness or wrongness of an action is grounded not so much in its actual or envisaged consequences, but in its disposition or propensity or causal power to produce certain consequences. On this proposal there is no troublesome time lag between action and consequences because an act and its causal powers exist simultaneously. But there are at least three serious problems with this proposal. First, and most obviously, powers are not consequences. So at best we are left with another version of quasi-consequentialism - one appears to be taking consequences seriously, but consequence are not right-makers. Second, there is the worry that it is metaphysically incoherent to think of actions per se as having causal powers or

\footnotetext{
${ }^{10}$ It is this consideration which rules out attempts to construe consequences not as the results of actions, but as an agent's reasons for preferring one action over another à la Portmore (2011).

${ }^{11}$ This sleight of hand is aided and abetted by the fact that justificatory reasons, i.e., right-makers (usually taken to be non-mental facts or states of affairs) and motivating reasons (beliefs and desires of agents) are not always as clearly distinguished as they ought to be.
} 
dispositions. It is much more natural to think that it is agents who bring about changes in the world by means of their actions. The relevant causal powers in question here are those of the agent, not the action, actions being nothing more than manifestations of the causal powers of the agent. On this line it would be the powers of the agent, powers which exist before the agent's actions, which are the right-makers - a result clearly at odds with consequentialism. But even if we set this quibble aside, a third problem arises. Assuming for the sake of argument that actions do have powers, the power of an action to produce certain consequences is inseparable from the action itself. That is, there is no real (as opposed to merely conceptual) distinction between an action and its alleged powers. That means that the powers, grounded in either the action ees occurent or modal properties, are intrinsic and not relational properties of the action. ${ }^{12}$ But a leading thought of consequentialism is that actions in and of themselves are morally neutral and only take on positive moral qualification in virtue of their relation to their good or bad consequences conceived of as distinct entities. The causal power approach does away with the ontologically real distinction between the act and its right-makers, and is thereby committed to saying, in concert with normative theories usually thought to be competitors, that it is something about the act itself which determines its moral status. This is to abandon prop. 3 .

And here we begin to see a general difficulty for the consequentialist: If one grants that the actual consequences do not exist at the time of the action, and one begins a search for alternative consequences to play the role of right-maker, one finds that the alternative consequences either fail to exist at the right time just as much as the actual consequences, or they exist where the consequentialist cannot admit them to be, i.e., in the mind or causal powers of the agent, or embedded in the action itself.

One further idea might be floated at this juncture. In an effort to avoid having to say that acts are morally neutral in and of themselves - a claim that often attracts criticism from other normative theorists - and to avoid the difficult ontological question of determining how to distinguish between an act and its consequences, some utilitarians

\footnotetext{
${ }^{12}$ It is important to distinguish between an object's propensity to $\mathrm{X}$ and its manifesting its propensity to $\mathrm{X}$. An object might require certain external enabling conditions to be met before its propensity to $\mathrm{X}$ can be manifested, but this does not make the propensity itself a relational property.
} 
have suggested that acts should be included among their consequences. For example, one finds Broome saying:

"If you perform an act, one consequence will be that you have performed it. If you break a promise, one consequence will be that you have broken a promise, and the wrongness of promise breaking can be taken as a bad feature of the consequences...In this way the intrinsic value of acts can be absorbed into teleology" (1995, 3-4).

If this approach were tenable it would allow the consequentialist to escape the dilemma without having to deny any of the initial propositions because an act and (at least one of) its right-making consequences would exist simultaneously.

But this is a desperate manoeuvre. For one, it seriously weakens the utilitarian ees claim to be offering a distinctive approach in normative theory. Moreover, it does not sit well with ordinary language to say, for example, that my having stolen your bike is a consequence of my having stolen your bike, for the two are one and the same thing. But most importantly, this approach equivocates on ,consequence ${ }^{e e}$. Of course from the point of view of world history one can say that if you break a promise it becomes true to say that you broke a promise. But this is not the sense of ,consequence ${ }^{e e}$ at issue in normative theory. The key sense of ,consequence ${ }^{e e}$ in normative theory is that of an effect in the nature of things (not truths) stemming from a cause. But in this sense causes cannot be effects of themselves on pain of metaphysical incoherence since self-causation involves existing and not existing at the same time.

\section{4}

The upshot of the last section is that it is far from obvious that the tensions between props. $1-6$ are merely prima facie. But the consequentialist can consider rejecting one or more of propositions $1,2,4,5$ or 6 . Let us take these in turn, dealing briefly with propositions 1 and 2 .

Can the consequentialist coherently deny prop. 1 and insist that human actions are not the sort of thing of which moral properties can be predicated, while maintaining that consequences are the only right-makers of actions? It would appear that the denial of prop. 1 and the assertion of prop. 3 lead to the straight contradiction that actions are and 
are not the sort of thing of which moral properties can be predicated. Similarly, can the consequentialist coherently deny prop. 2 , and insist that morally qualified actions do not require right-makers of any sort, while maintaining that consequences are the only rightmakers of actions? Again it would appear that the denial of prop. 2 and the assertion of prop. 3 lead to the contradiction that a relation to consequences both is and is not required for an action to be deemed right. But the deep problem for the consequentialist is that props. 1 and 2 are preconditions of normative theorising of any sort. Prop. 1 is a precondition of the viability of any theory seeking to provide a method of sorting actions into the various moral categories. To reject prop. 1 is to deny there is a call for any such theory because there is no such sorting to be carried out. Similarly with prop. 2. One of the main tasks of the normative theorist in general is precisely to identify and defend views regarding right-makers. To reject prop. 2 is to imply that the rightness or wrongness of actions need not be grounded in anything, that right and wrong might supervene on no being whatsoever. But this is to grant that the rightness or wrongness of actions is ultimately unintelligible since an action can be right while nothing makes it so. This is unacceptable to normative theorists of any description. It would appear then that props 1 and 2 are preconditions of prop. 3, so the consequentialist cannot resolve the dilemma by rejecting either of its first two propositions.

But other options remain. The consequentialist might explore the possibility of denying that the right-making relation requires the two relata to exist simultaneously. Now it is the standard view that real relations (as opposed to mere relations of reason) are dyadic, and so do indeed require the simultaneous existence of both relata. ${ }^{13}$ And there is certainly much to recommend this position. For example, it is hard to comprehend how $\mathrm{X}$ could have the relational property of being to the left of Y, say, if Y does not exist. But if one chose to deny this assumption then prop. 6 would be harmless. Here the consequentialist might take heart from the idea that indirect relations between relata appear to be possible. But while this tack has some plausibility in the case of currently existing entities and no longer existing entities, it is not so plausible going forward from

\footnotetext{
${ }^{13}$ This has been a common place for some time. For an extended discussion of the issue see Francisco Suarez (2006) On Real Relation (Disputatio Metaphysica XLVII). Translation by John Doyle. Milwaukee: Marquette University Press. See also Section VI of his (1995) On Beings of Reason (Disputatio Metaphysica LIV). Translation by John Dolye. Milwaukee: Marquette University Press.
} 
currently existing entities to not-yet-existing entities. One might think, for example, that one is currently indirectly related to one ${ }^{\text {ee }}$ great-great-great grandparents through the chain of intervening generations (each link having existed at some point). So one might grant that there is a sense in which every one of us is a great-great-great grandchild. But one cannot say of me, for example, that I am now a great-great-great grandfather in virtue of a relation obtaining now between me and my great-great-great grandchildren via a chain of progeny no link of which has ever existed. Most will think that entities which do not exist, and have never existed, cannot make a difference to the actual properties of currently existing entities, directly or indirectly. ${ }^{14}$ The consequentialist adopting this approach to the dilemma thus owes us an explanation as to how as-yet-to-exist consequences can make a difference to the actual properties of present actions.

But what of past consequences? Obviously individual acts have no past consequences of their own. But one way of exploiting the idea of indirect relations that would render prop.6 true but harmless would be to suggest that the consequences in virtue of which a particular current act is right or wrong are the consequences of past acts of the same type, not the as-yet-to-exist consequences of the current act. One could then suggest that the consequences of past acts of a certain type justify a rule forbidding or permitting acts of this type, and that a current act of this type is right if it is sanctioned by the rule, wrong if it contravenes it. This would allow prop. 6 to be true but harmless because consequences remain the only right-makers of the current act (albeit indirectly) despite the fact that they do not occur within the duration of the current act, and are not the consequences of the act in question.

There are a number of difficulties with this approach to the dilemma from a consequentialist point of view. Of course the appeal to rules of any sort is out of the question for act-consequentialists. But there is a significant problem with this account of

\footnotetext{
${ }^{14}$ This is certainly the view of Aristotle (Metaphysics, Book III, ch. 3, 998b20-27), and it is echoed by Aquinas (Summa theol. 1a2ae, q. 18, a.5); but it is likely to strike most as plausible independently of the respect one may or may not accorded to Aristotle or Aquinas. Of course one might say that I am currently at least potentially a great-great-great grandfather, but I do not have this property in virtue of my nonexistent progeny but in virtue of current biological facts about me. The same point applies to any causal relation. A cannot literally be the cause of B until B exists because to be a cause is to bring about an effect, and until $\mathrm{B}$ has been brought into existence there is no effect. Of course A may have the ability to bring about $\mathrm{B}$ in the right circumstances prior to $\mathrm{B}^{\mathrm{es}} \mathrm{s}$ existence, but this ability to cause B is distinct from actually bringing about $\mathrm{B}$.
} 
moral rules for all forms of consequentialism. Set aside the fact that the use of past consequences to justify rules governing current and future actions goes against the general future orientation of consequentialists of all stripes (what really matters for consequentialists is not what has happened in the past but what is going to happen in the future). The deep problem with the account of the moral rules is that it is inconsistent with consequentialism. For the past consequences of acts of a certain type would justify a rule permitting or forbidding current tokens of this type only if there were a reliable, i.e., non-accidental, connection between acts of this type and their consequences. It is this non-accidental connection, after all, which explains why acts of this type have been followed by the standard consequences of the type, which is why acts of this type should be avoid. But the most natural account of this reliable connection, should one exist, is that it is in virtue of the intrinsic properties of the act type that its tokens have the propensity to bring about the standard consequences of the type. But we have already seen the problems associated with appealing to propensities or causal powers. In such cases the rightness or wrongness of an action is ultimately grounded in the intrinsic properties of actions themselves, properties the actions will have even if they fail to bring about their standard consequences. Clearly no consequentialist could accept this, so the postulated indirect right-making relation via rules between past consequences and current acts breaks down. The natural way for a rule-consequentialist to justify a rule is precisely analogous to the manner in which act-consequentialists justify acts, i.e., by appeal to their future consequences. But this lands the consequentialist right back in the dilemma with which we started.

Another approach would be to explore the possibility of denying prop. 5 in order to be able to maintain that an action is morally neutral at the time it is performed, but becomes right or wrong subsequent to its passing out of existence. As noted earlier, this option sits poorly with ordinary moral thinking. It also comes at the cost of admitting that non-existent entities, in this case completed past actions, can undergo change. It is far from obvious that good ontological sense can be made of this suggestion. In fact it seems quite obvious that no such changes are in fact possible. But for the sake of argument let us consider the possibility that the consequentialist wants to exploit the notion of socalled „Cambridge changese to save the situation. Let us grant that it is coherent to say, 
returning to Prior ${ }^{\text {ee }}$ example, that Queen Ann, now long dead, to this day undergoes change in the sense that she becomes more and more past in the relation to the present, and will continue to become more past with each passing day. On this line one can say that Queen Ann continues to get older despite the fact that she does not exist. If the consequentialist accepts Cambridge changes as real changes, she could say that completed past actions can and do undergo change in moral status as their consequences are eventually actualised, and so deny prop. 5. But even if we grant the metaphysical coherence of this position, it certainly leads to awkward results for the coherence of consequentialism as a normative theory. For the result is that an action will either repeatedly change in moral status as consequences of different quality are actualised, or remain without a moral status until the totality of the action ${ }^{\text {ee }}$ consequences have been actualised. Neither is a welcome result for the consequentialist. For it is a curious position that maintains that one and the same action can be right at one moment, wrong at a later moment, and then right again for a period of time before reverting again to the bad books - all while not existing at all. This might be a result some consequentialists could accept. But many will find it far too dear, if only because it is not clear that such a theory could ever serve as a guide to action. ${ }^{15}$ The alternative is to say that completed past actions remain morally neutral until the totality of their consequences have been actualised. Setting aside the epistemological problem of determining whether the totality of an action $^{\text {ee }}$ consequences have been actualised, this approach entails that actions will get their moral status far too late for the agent to have reason to care about the rightness or wrongness of actions. If an action will only become right/wrong long after all the immediate participants have left the scene, it becomes difficult to explain why we care so much about each otheres actions here and now. ${ }^{16}$

A final option remains. The consequentialist can deny prop. 6 , and insist that all the morally relevant consequences of an action exist at the time of the action itself. There are many ways in which this claim might be understood. First, one might deny prop. 6 because one identifies actions with their consequences, in effect denying separate

\footnotetext{
${ }^{15}$ Imagine someone arguing as follows: „I know this war is wrong now; but don"t worry, it will be right in a couple of years. Of course it might very well revert to being wrong again, but let"s keep our fingers crossed."

${ }^{16}$ Imagine some one arguing as follows: „Don't worry about this war; it won't be wrong till we're long gone.
} 
existence to actions and their consequences. If the duration of an action "es performance is limited only by its consequences (because the consequences are simply part of the action itself) then the difficulty of accounting for grounding relations between an existing entity and a non-existent entity is avoided. ${ }^{17}$ A second way to understand the denial of prop. 6 is to maintain that actions and their consequences are distinct entities, pace the initial suggestion, but that consequences still exist in some sense at the time of the action $\mathrm{s}$ performance. There are several ways this might be attempted. One might try to argue that an action ${ }^{e e}$ s consequences pre-exist virtually in the action itself. ${ }^{18}$ Alternatively, one could reject an assumption of the dilemma, namely, that only present entities are real, and embrace eternalism, or the ,block view ${ }^{e e}$ of space-time, i.e., the claim that past, present and future entities and events are equally real. ${ }^{19}$ If eternalism is true, then an action ${ }^{\text {ee }} \mathrm{s}$ consequences are available to play the role of right-maker at the time required after all. Finally, one could embrace possibilia and argue that while an action ${ }^{\text {ee }}$ actual consequences do not exist in any sense at the time of the action (pace eternalism), an action nonetheless has an immediate impact on the set of possible futures open to the agent prior to the action. The idea then is to ground an action ${ }^{\text {ee }}$ sightness or wrongness in its relation to simultaneously existing possibilities. ${ }^{20}$ If one can think of an action as having effects on real possibilities, eliminating some while leaving others open, one could judge an action right if it leaves the best of the available possibilities open, and wrong otherwise.

These are the most interesting alternative solutions from a metaphysical point of view. But it is far from obvious that they can be made to work in a way congenial to consequentialists. Dropping the distinction between an act and its consequences, for

\footnotetext{
${ }^{17}$ It is worth noting that this is more than a theoretical possibility. Dasgupta has suggested something very close to this position as a way of overcoming what he takes to be the overly crude distinction between acts and consequences upheld by deontologists and utilitarians. He writes: "If actions matter intrinsically, they can be made part of the description of consequences, and then the distinction collapses (1993, p.30)."

${ }^{18}$ This was a relatively common view amongst the Scholastics. Aquinas, Summa theol. 1a2ae.q. 20, a. 5, provides a detailed discussion of this possibility: „It would seem that the consequences of the external act increases its goodness or badness. For the effects pre-exist virtually in its cause. But the consequences result from the act as an effect from its cause. Therefore they pre-exist virtually in the acts. ${ }^{e}$

${ }^{19}$ Eternalism is a species of four-dimensionalism, according to which „... there are past or future objects (or both); and in saying this, [four-dimensionalists] mean to put such things ontologically on a par with present objects. According to the four-dimensionalist, non-present objects are like spatially distant objects; they exist, just not here, where we are" (Rea, 2005, 246).

${ }^{20}$ The literature on possibilia is enormous. For a useful discussion of the problems associated with such entities see Fine (2005).
} 
instance, requires abandoning the claim that actions are morally neutral in and of themselves because an action ${ }^{\text {ee }}$ s right-maker is now an intrinsic rather than a relational property of the action. So this option in not open to the consequentialist. ${ }^{21}$

As for virtual existence, the scholastic metaphysicians spoke of this mode of existence in a number of ways. For example, one could say that the elements of a compound (as opposed to a mixture) exist virtually in the compound. The idea here is that the elements continue to exist in some sense (since they can be retrieved from the compound by means of chemical processes) but they do not exist as entities in their own right with their own characteristic powers and liabilities because they are harnessed to the operations of the compound in which they exist. ${ }^{22}$ But this notion of virtual existence does not provide a useful model for the consequentialist since the relation of elements to compound is such that the elements can and often do exist prior to the compound, whereas there is no sense in which the consequences of an action can exist prior to the action itself. But it was also common to say that effects pre-exist virtually in their causes, by which they meant that a cause has the power to bring about its characteristic effects. So to say that an action "es consequences pre-exist virtually in the action itself amounts to the claim that actions have the power or propensity to bring about certain consequences. ${ }^{23}$ But, as already suggested, this is not congenial to consequentialism in its contemporary formulations either since powers and propensities are grounded in intrinsic properties of actions. So the consequentialist tempted to employ the notion of virtual existence must

\footnotetext{
${ }^{21}$ This is not a particularly attractive line of thought anyway since it has little to recommend it on independent grounds. It certainly does not receive any support from the standard views of the ontology of action. See Lowe (2010) for discussion. For example, if we take it that actions are ultimately movements of an agent"s body, then an action"s consequences cannot be part of the action itself, contra the suggestion, since the vast majority of an action's consequences as standardly conceived are not movements of the agent"s body. But if we revise our notion of consequences, limiting them to the movements of the agent"s body, then the action's consequences will seldom (if ever) be that in virtue of which an act is right or wrong. On the other hand, if we hold that an action is the exemplification of a certain property by a certain object at a certain time, then again the consequences of an action cannot be part of the action itself since the vast majority of these cannot be plausibly construed as properties of any one particular object at any time.

${ }^{22}$ This notion of virtual or potential existence has its roots in Aristotle. In On Generation and Corruption, Bk 1, ch. 10 he writes: "Since, however, somethings are-potentially while others are-actually, the constituents combined in a compound can „be ${ }^{e c}$ in a sense and yet ,not-bee $e^{e}$ The compound may be-actually other than the constituents from which it has resulted; nevertheless each of them may still be-potentially what it was before they were combined and both of them may survive undestroyed." As a side note it might be worth pointing out that this view remained common in the early stages of the development of modern chemistry, but has now been replaced by the actual components thesis following the adoption of Mendeleev's Periodic Table of Elements.

${ }^{23}$ See note 18 above. See note 31 below for more on Aquinas and consequentialism.
} 
explain how an action can contain its consequences while maintaining the real distinction between them.

As for the recourse to eternalism, there is no doubt that four-dimensionalism is a very popular view of time in metaphysical circles. ${ }^{24}$ But it has unwelcome implications for normative theorists. In particular it threatens to undermine assumptions that must be in place for normative thinking to have any point at all. One purpose of normative thinking is to determine what one ought to do in a particular situation - the assumption being that one is not already performing the action in question but merely deliberating about possibly performing the action. But if eternalism is true, one is already performing the action one is considering performing, and the consequences of this same act already exist (for future entities exist on a par with present entities). Apart from coherence issues, ${ }^{25}$ it is far from obvious what the ethical point of one ${ }^{\text {ee }}$ s deliberations might be in such circumstances. But a further assumption of normative thinking is that the future is open and that we have genuine options from which to choose, hence the need for deliberation. But fatalism looms if eternalism is true. And if fatalism is true, the notion of a voluntary action is under threat. And if voluntary actions are cast into doubt, then prop. 1 is undercut. For the only actions normative theorists wish to sort into the various moral categories are voluntary actions. If there are no voluntary actions, there is no sorting to carry out. ${ }^{26}$ This leaves the consequentialist in a particularly difficult position, for there is no theory of the ontological status of future entities and events which is congenial to consequentialism. If future entities and events do not exist (as presentists would have it) consequences do not exist at the time required to play the role of right-makers. But if future entities and events do exist on a par with current entities and events (as eternalists would have it) then fatalism looms and there are no voluntary actions to be sorted into the moral categories at all. Either way, consequentialism fails.

This leaves recourse to possibilia. If one assumes for the sake of argument that talk of possibilities is both intelligible and factual then one is likely to advert to possible

\footnotetext{
${ }^{24}$ Defenses of the opposing view, presentism, are relatively rare. But some can be found. See Bourne (2006) for a book length discussion. See also Crisp (2005).

${ }^{25}$ Perhaps the most pressing difficulty is doing justice to the intuition that we currently occupy the present. If eternalism is true it becomes very difficult to determine whether one is living in the past, present or future. See Bourne (2006) for discussion.

${ }^{26}$ Some have taken this problem to constitute perhaps the most serious challenge eternalism faces. See chapter 7 of Bardon"s (2013) for extended discussion.
} 
worlds when giving an account of the nature of possibilia. Carlson, for example, maintains that "...the (morally relevant) outcomes of actions are, for a consequentialist, most plausibly identified with possible worlds, or total world histories ... [t]he outcome of an action is the future that would be actual if the action were performed" $(1995,2){ }^{27}$ The idea then is to advert to possible worlds as right-makers because these exist at the same time as the actions they make right, and so extricate us from our dilemma.

There is much that could be said about this approach, but let us assume for the moment that talk of possible worlds is intended to be more than a heuristic devise when navigating the tricky domain of modal logic and is meant in all metaphysical seriousness. ${ }^{28}$ Since the consequentialist hoping to avail herself of possible worlds is forced to adopt a realist interpretation of possible worlds talk if possible worlds are to serve as right-makers, deflationary or fictionalist views of possible worlds are ruled out. Now realist views of possible worlds come in two varieties. On one such view possible worlds are wholly distinct concrete entities existing in the same sense as this, the actual,

\footnotetext{
${ }^{27}$ This line of thought has proved very popular. It is exploited by Fred Feldman in his (1986) and (1997) according to whom the consequences that count are possible worlds accessible from this world. Others include Michael Zimmerman (2001), Chisholm (2005), and Derek Parfit (2011).

${ }^{28}$ This is not an unproblematic assumption. The seriousness with which possible worlds talk has been taken in the analytic tradition is one of the most perplexing features of the revival of metaphysics in $20^{\text {th }}$ century. Originally the idea was that progress could be made in the domain of modal logic by trading on similarities between the logical relations of "all/some" propositions on the one hand and those of "necessary/possible" propositions on the other. Since the logic of "all/some" propositions is well known, it was thought that great strides would be made in modal logic if it could be seen as simply a special case of the logic of "all/some" propositions since a necessary truth was taken to be a truth in all possible worlds, a possible truth a truth in some possible world. However, it was always obvious that no real insight into the metaphysical nature of necessity and possibility was going to be forthcoming from this approach since modal notions were built into the very notion of a possible world. As Lowe trenchantly points out: “...this explication is no clearer than the key notion of a ,possible world "e upon which it draws... [but] this notion is thoroughly obscure and really of no use at all in explicating either the notion of necessity or the metaphysical grounds of necessary truth" $(2015,6)$. The deeper complaint against the seriousness with which possible worlds talk has been taken by metaphysicians is that it conflates logical necessity and possibility with metaphysical necessity and possibility. But modal logic is the study of entailment relations obtaining between modal propositions, while metaphysics is (in part) the study of the non-logical relations obtaining between extra-mental entities in the various ontological categories. Unless one believes that the only necessities and possibilities are logical necessities and possibilities, this conflation of logic and metaphysics is unwarranted, and one cannot take possible worlds talk as a serious contribution to metaphysical reflection. But ethicists can perhaps be forgiven for helping themselves to possible worlds talk since there was a licence to do so given its currency among contemporary metaphysicians.
} 
world. On the other most common realist view, possible worlds are abstract objects, perhaps maximally consistent sets of propositions. ${ }^{29}$

But neither of these options should appeal to consequentialists tempted to consider this general approach to the dilemma. Possible worlds, however they are construed, are simply not plausible right-makers of concrete actions occurring in this the actual world. For the cost of this proposal is maintaining that changes in sets of propositions, or changes in the set of concrete but wholly distinct worlds, are the rightmakers of actions in this actual world despite the fact that neither kind of change bears any concrete causal relation to these actions. Moreover, on neither reading of possible worlds talk do the alleged right-makers have anything to do with those actually affected by the actions here in this world; but surely it is these effects that matter from a moral point of view. So even if changes in concrete possible worlds or sets of abstract propositions could be construed as consequences of actions in this the actual world, and it is not clear that they can be, these changes are not credibly seen as the changes in virtues of which actions are right or wrong.

Another account of possibilia is available, however. On this account concrete possible worlds and abstract sets of propositions are dispensed with in favour of the view that possibilia supervene on the way things actually are with concrete entities in the actual world. On this view possibilia are absolutely nothing outside of their causes - to use a scholastic turn of phrase - inasmuch as they are nothing more than the powers and liabilities of actual objects. On this account to say that a given state of affairs is possible is to say that this state of affairs will be brought about should actual objects with the relevant corresponding powers and liabilities be brought into sufficiently close proximity to allow those powers to be manifested.

Now this view of possibilia does maintain an intimate connection with real things in the actual world, and so is far more in keeping with the needs of normative theorists than those adverting to possible worlds. But close inspection reveals that this approach is not really open to the consequentialist because it threatens to collapse as a distinct form of normative theorising. And this is because possibilia so conceived are difficult to

\footnotetext{
${ }^{29}$ I set aside for present purposes the possibility of accepting a mixed view according to which some possible worlds are concrete entities (i.e., this actual world) while others are abstract objects (all the remaining possible worlds). I set this aside because it does not affect our argument.
} 
distinguish from Aristotelian potentialities which play such a prominent role in the framing of traditional natural law theory (see $\S 6$ for more on this). For an objectes powers and liabilities are grounded in the essential nature of the object. It is the essential nature of agents and those affected by their actions - in conjunction with the natures and configuration of objects in the agent ${ }^{e c}$ s field of concern - which set the limits of possibility for that agent. The basis of this view is the intuition that what $\mathrm{x}$ is essentially determines what $\mathrm{x}$ can become (temporal possibility) as well as what $\mathrm{x}$ could have been (counterfactual possibility) and what $\mathrm{x}$ can do. ${ }^{30}$ Some will object in principle to any appeal to natures or essences, in which case this tack is no longer an option. But for consequentialists willing to countenance essentialism, the challenge becomes maintaining a distinct form of normative theorising. For if one thinks of actions as being right or wrong in virtue of their effects on the possibilities open to agents, possibilities that supervene upon the essential natures of those involved, then consequentialism is now making common cause with versions of natural law theory, a normative theory usually considered to be a competitor. For a theory of the good based on possibilities so conceived will quite naturally take natures, and human nature in particular, to be its touchstone. For on this approach human nature is the beginning and the end of human action. It is the beginning insofar as human actions are manifestations or exercises of our distinctive powers grounded in our distinctive human nature. So knowing what is possible for humans depends implicitly on knowing human nature. But human nature is also the end of human action inasmuch as distinctly human well-being, the good to be pursued, is determined by the sort of creature we are. It then becomes quite natural to think that the consequences an agent ought to promote are the realisations of the potentials of those affected by the action. That is, it becomes natural to think that an

\footnotetext{
${ }^{30}$ The case for this claim lies beyond the bounds of this paper, but it is to be found in metaphysicians of some repute. For example Lowe writes: „It is incumbent on metaphysicians to explain what it is that grounds metaphysical possibility - and to do so in a way that allows our knowledge of metaphysical possibility to be something that is itself possible [...] My own belief [...] is that the only coherent account of the ground of metaphysical possibility and of our capacity for modal knowledge is to be found in a version of essentialism: a version that I call serious essentialism, to distinguish it from certain other views which may superficially appear very similar to it but which, in fact, differ from it fundamentally in certain crucial respectse $^{\text {ee }}(2006: 1)$.
} 
action is right if it helps those affected by the action to flourish. This is consistent with consequentialism; but it is music to the ears of natural law theorists.

\section{5}

To sum up the argument so far: Since it is a dereliction of philosophical duty simply to accept or to ignore contradictions in one ${ }^{e e}$ s belief set; and since the consequentialist cannot restore consistency by rejecting all of the propositions without abandoning consequentialism itself, the consequentialist must show the tensions to be merely prima facie or abandon prop. 4, 5 or 6 . I have argued that it is far from obvious that the tensions are merely prima facie. So the pressure remains firmly on proposition 3, for the cost of saving consequentialism is to embrace one of these unpalatable alternatives:

a. The minuscule sub-set of actual consequences that does exist within the duration of the action are the right-makers of that action

b. Insist that entities which do not exist, and have never existed, can make a difference to the actual properties of currently existing entities, thereby denying that real relations require the simultaneous existence of subject, term and foundation

c. Accept that non-existent entities can undergo change

d. Maintain that an action "s consequences pre-exist virtually in the action itself

e. Embrace eternalism

f. Insist that an action es moral status is grounded in a relation to possible worlds conceived of either as abstract objects or as wholly distinct concrete objects

g. Insist that an action se moral status is grounded in a relation to possibilities supervening on the natures of those affected by the action. 
(a) and (f) saddle the consequentialist with wholly implausible right-makers. (b) and (c) are of dubious coherence. On the face of it (d) compromises the moral neutrality of actions, and so awaits a plausible interpretation consistent with consequentialism. (e) appears to undermine the point of all normative theorising. On (g) consequentialism ceases to be a distinct approach to normative theorising. These costs will give the prudent consequentialist cause to reconsider their commitment to prop. 3.

\section{6}

The primary aim of this paper has been to show that consequentialism has yet to receive a metaphysically coherent formulation. But even if one were inclined to agree with the general thrust of $\S \S 1-5$, serious doubts remain. At the outset of this paper it was acknowledged that there is something intuitively plausible about the contention that the results of our actions matter from a moral point of view. But if the argument of this paper is on the right track, then our understanding of the moral import of consequences is faulty. Consequences cannot be right-makers, let alone the only right-makers. But can this really be right? If consequentialism is in fact metaphysically incoherent, how has this escaped notice? And wouldn ${ }^{e e}$ the denial of consequentialism mean that we should not or need not care about the future, or our responsibilities to future generations? Is that morally plausible? And what, after all, is wrong with quasi-consequentialism if that is what consequentialists have always really had in mind?

The upshot is that we are faced with a second dilemma. On the one hand it would seem that consequentialism is indeed incoherent. But at the same time it seems implausible to deny the intuitions that lead the unsuspecting into the arms of consequentialism. I want to end with a sketch of a suggestion that holds out hope of a resolution. What is needed is a metaphysically coherent approach to normative theorising that does justice to the core intuitions of consequentialism without committing its metaphysical errors. This suggestion, one that can only be waved at here, is to take $(\mathrm{g})$ seriously in conjunction with the various forms of quasi-consequentialism identified above. 
Let us begin by acknowledging the pressures that induce serious thinkers to embrace consequentialism. The first is the obvious fact that consequences at least appear to matter. The second is the equally obvious fact that the moral value of tokens of action types is not constant, so a simple-minded deontology is not viable. The third is that the

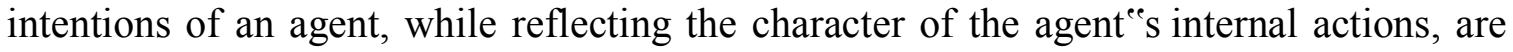
not reliable indicators of the moral value of the agent ${ }^{\text {ee }}$ external actions that result from those intentions. It is points like these which make consequentialism attractive, and we need to find some way of accommodating these intuitions.

My suggestion is that in lieu of consequentialism we entertain a theory of practical rationality the basic principles of which are as follows ${ }^{31}$ :

i. Our desiderata, qua act centred normative theorists, are principles of practical rationality that allow one to distinguish between reasonable (right) and unreasonable (wrong) actions. ${ }^{32}$

ii. A reason for acting is some possible good to be pursued or a possible bad to be avoided. ${ }^{33}$

iii. Something is a good if it promotes human health, physical, emotional, psychological and social. $^{34}$

iv. An action is reasonable/right if it is a non-defective response to a good.

v. A response is non-defective if (a) it is a token of a kind of action which tends to maintain and promote the widespread distribution of goods among those affected by the action ${ }^{35}$; (b) a token of that kind is appropriate in the specific circumstances of the action; ${ }^{36}$ and (c) the primary intention motivating the agent is to bring about the good associated with actions of that kind.

\footnotetext{
${ }^{31}$ This account sticks very closely to traditional natural law theory, but leans heavily on Murphy (2001).

${ }^{32}$ Here is Aquinas on the identification of right and reasonableness: "Now in human actions, good and evil are predicated in relation to the reason, because... the good of man is to be in accordance with reason, and evil is to be against reason" (Summa Theologiae, I-II, q. 18, a.5).

${ }^{33}$ This is the principle of synderesis in the terminology of traditional natural law theory. Here ,possible ${ }^{e e}$ is to be taken as sketched at the end of $\S 5$.

${ }^{34}$ Again, in the terminology of traditional natural law theory, one would say that the good or the virtuous is that which is "conducive to well-living" - utlitas ad bene vivendum (Aquinas, Summa Theologiae, I-II, q. 94, a. 3). Uncontroversial goods include whatever preserves human life - adequate nutrition, potable water, serviceable clothing, shelter - and whatever preserves human society and the benefits derived from the social order - security, education, health care, to name only a few examples.

${ }^{35}$ Examples of plausible kinds include those correlated with Ross"s (2002) prima facie duties: duties of fidelity, reparation, gratitude, beneficence, justice.

${ }^{36}$ On the importance of circumstances, see Aquinas, Summa theologiae, I-II, q. 18, a. 3. This is essentially Aristotle"s point that an action is right if it is done at the right time, to the right extent, by the right person, to the right people, in the right way, with the right implements, etc.
} 
vi. Conditions (a), (b), and (c) are individually necessary and jointly sufficient for an action to be right. Failure in any one respect entails a defective response to a good. ${ }^{37}$

vii. There are degrees of defectiveness. Sometimes what one does is objectively defective, but the act might remain acceptable, if not wholly so, because it is the least defective response available in the circumstances.

viii. Because what constitutes human health is determined by a universal human nature, the principles of practical rationality are universally binding. ${ }^{38}$

ix. These principles are knowable largely through empirical means.

Now it is not my purpose here to defend this theory of practical rationality. It will do if we can agree that it is at least worthy of consideration because it resolves our second dilemma. The point for present purposes is that, without ever falling into the incoherencies of consequentialism, it can accommodate many of its core intuitions. For one, it agrees with the consequentialist that the good is prior to the right. Moreover, consistent with consequentialism proper, neither agent intention nor kinds of actions are considered normative trump cards; nonetheless both intentions and action types are given important roles in ethical theorizing consistent with forms of quasi-consequentialism. One such view was that it is an action's causal power to bring about certain consequences that matters. This is accommodated above by the insistence that an action ${ }^{\text {ee }}$ kind is morally significant because it is the action "s kind that determines which causal powers it has. ${ }^{39}$ Another quasi-consequentialist view was that the consequences that matter are those intended or envisaged by the agent and which play the role of reasons in

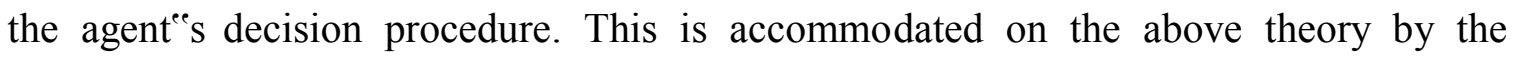

\footnotetext{
${ }^{37}$ Aquinas writes: "Nothing hinders an action that is good in one of the ways mentioned above from lacking goodness in another way. And thus it may happen that an action which is good in its species or in its circumstances is ordained to an evil end, or vice versa. However, an action is not good absolutely, unless it is good in all those ways; for evil results from any single defect..." (Summa Theologiae, I-II, q. 18, a. 4).

${ }^{38}$ That human nature is universal follows from our identification of that nature with our species specific developmental programme. For extended discussion of this idea drawn from developmental biology, see West-Eberhard (2003), Raff (1996) and Boulter (2012).

${ }^{39}$ Consider Aquinas: “...the goodness of an action is not caused by the goodness of its effect, even though an action is said to be good from the fact that it can produce a good effect" (Summa Theologiae, I-II, q. 18, a. 2, ad. 3). Aquinas 's point is that an action has a nature in virtue of its type which contributes to the rightness or wrongness of tokens of that type. This is inconsistent with consequentialism, and it goes against the commitment to the moral neutrality of actions in and of themselves, but it is precisely what a quasi-consequentialist could endorse.
} 
insistence that the agentes intention is morally significant: if an agent "s primary intention in acting in a certain way is to actualize the goods associated with actions of that kind, then one of the three necessary conditions of a non-defective response to a good has been secured. Such a theory, I suggest, provides the framework for an approach to normative theorizing that accommodates consequentialism "s key intuitions without metaphysical incoherence, thus addressing our second dilemma.

A few final outstanding points: First, does such a theory lead one to disregard our obligations to future generations? The short answer is that it should not. Of course, our regard for the future must be metaphysically coherent. But this is not difficult to establish. If we insist, as surely we must, that change is inevitable, and that not all change is welcome, it follows quite naturally that we will be concerned about which possible changes will be actualised. To keep these possibilities from becoming ethically irrelevant or metaphysically dubious we must insist that real possibilities are grounded in the natures of currently existing things. Finally, if we accept that real possibilities are actualised in many instances by our own actions, we reach the result that it is both metaphysically coherent and ethically mandatory to care about how our actions affect "the future". Nothing in the line of argument offered in previous sections undercuts a concern for the future when understood in this sense.

Second: If consequentialism proper is in fact incoherent, how has this escaped notice? Two possible explanations suggest themselves. First, quasi-consequentialism, which is not incoherent, is very easy to confuse with consequentialism proper, for both place an emphasis on consequences. And if one is not attending to metaphysical niceties the differences can easily go unnoticed. Second, both insist on the slogan "the good is prior to the right". But what often goes unremarked is that priority comes in different types. The good is indeed prior to the right in the order of knowledge; but it is not prior in the order of being. ${ }^{40}$ By failing to mark this distinction in kinds of priority consequentialists proper have misconstrued the role of consequences in normative theorising.

Finally, could the consequentialist not just rest content with quasiconsequentialism? What is wrong with quasi-consequentialism, particularly if that is

\footnotetext{
${ }^{40}$ This is another way of making the point Aquinas draws attentions to in note 39.
} 
what consequentialists really had in mind all along? Does the consequentialist really need to cosy up to natural law theory? The response to this is twofold: First, there is nothing wrong per se with quasi-consequentialism. In fact, as suggested above, quasiconsequentialist views are parts of a defensible approach to normative theorising. The problem as far as the present argument is concerned is simply that quasiconsequentialism is not a form of consequentialism at all. Quasi-consequentialism admits that consequences are never right-makers (let alone the only right-makers); but the rightmaker thesis enshrined in prop. 3 is the distinctive claim of anything worth calling consequentialism. But, and this is the second response, by hanging on to the name but not the substance of consequentialism, quasi-consequentialists are in danger of obscuring the real nature of their own normative theorising. In particular the quasi-consequentialist is liable to miss the point that they are no longer offering a truly distinctive normative theory at all: For there is little "clear blue water" between quasi-consequentialism and traditional natural law theory, only the latter is more developed and far more sophisticated. But if the association with natural law theory is too much to bear for the quasi-consequentialist, the only alternative is to drop consequentialism in name as well as in substance.

\section{REFERENCES}

Aristotle (1941) Metaphysics. In The Basic Works of Aristotle. McKeon (ed.). New York: Random House.

Aquinas, Thomas (1997) Basic Writings of Saint Thomas Aquinas. Pegis (ed.) Indianapolis: Hackett Publishing.

Bergstrom, Lars, (1973) „On the Coherence of Act-Utilitarianism“e, Analysis, Vol. 33, No. 3, 98-102.

(1976) ,On the formulation and application of Utilitarianism“, Nous, Vol. 10, No. 2, 121-144.

Bardon, Adrian (2013) A Brief History of the Philosophy of Time. Oxford: Oxford University Press.

Boulter, Stephen (2012) "Can Evolutionary Biology do without Aristotelian Essentialism?", in Human Nature. Royal Institute of Philosophy Supplement: 70. Sandis and Cain (Eds). Cambridge: Cambridge University Press, pp. 83-104.

Bourne, Craig (2006) A Future for Presentism. Oxford: Oxford University Press. Broome, John (1995) Weighing Goods: Equality, Uncertainty and Time. Oxford: Blackwell.

Carlson, Erik (1995) Consequentialism Reconsidered. AA Dordrecht: Kluwer. 
Castaneda, Hector (1968) „A problem for utilitarianism“, Analysis, Vol. 28, No. 4, 141142.

Chisholm, Roderick (2005) "Objectives and Intrinsic Value", in Recent Work on Intrinsic Value. Ronnow-Raismussen and Zimmerman (eds.). AA Dordrecht: Kluwer.

Crisp, Thomas (2005) „Presentism“, in The Oxford Handbook of Metaphysics. Loux and Zimerman (eds). Oxford: Oxford University Press, 211-245.

Dasgupta, Parth (1993) An Inquiry into Well-Being and Destitution. Oxford: Oxford University Press.

Drivers, Julia (2007) Ethics: The Fundamentals. Oxford: Blackwell.

Feldman, Fred (1986) Doing the Best We Can: An Essay in Deontic Logic. Springer. (1997) Utilitarianism, Hedonism and Dessert: Essays in Moral Philosophy. Cambridge: Cambridge University Press.

Fine, Kit (2005) „The problem of possibiliae, in The Oxford Handbook of Metaphysics. Loux and Zimmerman (eds). Oxford: Oxford University Press, 161-179.

Lowe, Jonathan (2006) The Four-Category Ontology. Oxford: Oxford University Press. (2010),Action Theory and Ontologye, in A Companion to the Philosophy of Action. (O'Connor and Sandis (eds). Oxford: Blackwell, 3-9.

Murphy, Mark (2001) Natural Law and Practical Rationality. New York: Oxford University Press.

Parfit, Derek (2011) On What Matters. Oxford: Oxford University Press.

Pettit, Philip (1997) „Consequentialism“, in A Companion to Ethics. Singer (ed.) Oxford: Blackwell, 230-240.

Portmore, Douglas (2011) Commonsense Consequentialism: Wherein Morality Meets Rationality. Oxford: Oxford University Press.

Prior, Arthur (1968) Time and Tense. Oxford: Oxford University Press.

Quinton, Anthony (1989) Utilitarian Ethics. London: Duckworth.

Raff, R. (1996) The Shape of Life: Genes, Development, and the Evolution of Animal Form. Chicago: University of Chicago Press.

Rea, Michael (2005) „Four-Dimensionalism ${ }^{e}$ In The Oxford Handbook of Metaphysics. Loux and Zimmerman (eds). Oxford: Oxford University Press, 246-280.

Ross, David (2002) The Right and the Good. Oxford: Oxford University Press.

Suarez, Francisco (2006) On Real Relation (Disputatio Metaphysica XLVII). Translation by Doyle. Milwaukee: Marquette University Press.

Sinnott-Armstrong, Walter (2011) „Consequentialism ${ }^{\text {ee }}$ in The Stanford Encyclopaedia of Philosophy (Winter 2011 Edition) Edward N. Zalta (ed.) forthcoming $\mathrm{URL}=$,http://plato.standford.edu/archives/win2011/entires/consequentialism/>.

West-Eberhard, M.J. (2003) Developmental Plasticity and Evolution. USA: Oxford University Press.

Zimmerman, Michael (2001) The Nature of Intrinsic Value. Lanham MD: Rowman and Littlefield. 